Title

\title{
On-chip glucose detection based on glucose oxidase encapsulated on a platinum modified gold microband electrode
}

Author names and affiliations

Julia Madden ${ }^{1}$, Colm Barrett ${ }^{1}$, Fathima Laffir ${ }^{3}$, Michael Thompson ${ }^{1,2}$, Paul Galvin ${ }^{1 *}$ and Alan O' Riordan ${ }^{1 *}$

${ }^{1}$ Tyndall National Institute, University College Cork, Lee Maltings, Cork, Ireland.

${ }^{2}$ Department of Chemistry, University of Toronto, Canada

${ }^{3}$ Bernal Institute, University of Limerick, Limerick, Ireland

E-mail Addresses: julia.madden@tyndall.ie, colm.barrett@tyndall.ie, fathima.laffir@ul.ie, m.thompson@utoronto.ca, paul.galvin@tyndall.ie and alan.oriordan@tyndall.ie.

* Correspondence address: Tyndall National Institute, Lee Maltings, University College Cork, Cork, Ireland. E-mail address: alan.oriordan@tyndall.ie and paul.galvin@tyndall.ie

Highlights:

- Gold microband electrodes with a total surface area of approximately $50 \mu \mathrm{m}^{2}$ were characterised and modified towards mediator-free on-chip glucose detection.

- Glucose oxidase was electrochemically deposited in a mixture of $o$-Phenylenediamine and $\beta$-cyclodextrin on to the single platinum modified gold microband electrode.

- The biosensor developed using a two-step electrodeposition process achieved a linear response to glucose detection in the range of 2.5-15.5 $\mathrm{mM}$.

\section{Abstract}

We report a two-step electrodeposition process incorporating glucose oxidase onto a platinum- modified gold microband electrode with an o-phenylenediamine and B-cyclodextrin mixture. The bare microband electrodes were fabricated on silicon using standard microfabrication methods i.e. lithography and etching techniques. The two-step electrode modification process was characterized using cyclic voltammetry, electrochemical impedance spectroscopy and scanning electron microscopy. The enzymatic based microband biosensor exhibited a linear response to glucose from 2.5-15 mM using both linear sweep voltammetry and chronoamperometric measurements in buffer based solutions. The resulting miniaturized 
glucose sensor presented a number of advantages such as ease of use, fast response time, measuring within physiologically relevant glucose concentrations in addition to sensing in small sample volumes without the need for an external counter and reference electrode. The biosensor performance was tested in $30 \mu 1$ volumes of undiluted fetal bovine serum. Whilst a reduction in signal was evident within $100 \%$ serum samples, the sensor achieved linear glucose detection with increasing glucose concentrations (2-12 $\mathrm{mM})$.

Keywords: microband, glucose detection, enzymatic, electrochemical, microfabrication, silicon

\section{Introduction}

Electrochemical glucose sensor developments continue to be of significant interest for their application in a variety of fields including human health (Lisi et al., 2020), animal health (Corradini et al., 2016), bioprocess monitoring (Jin et al., 2020) in addition to monitoring in the food and beverage industries (Cinti et al., 2020, Pontius et al., 2020). Fabrication of siliconbased electrodes are valuable for the development of miniaturized electrochemical sensors as various electrode designs, dimensions and configurations can be fabricated on a compact electroanalytical device (Li et al., 2018, Fekete, 2015). Micro and nanoscale electrodes have become increasingly popular towards the development of electrochemical based biosensors as a result of their lower detection limits, higher signal to noise ratio in addition to their ability to achieve steady-state currents (Li et al., 2019, Streeter et al., 2007). In the present work, we describe a single gold band electrode which is $45 \mu \mathrm{m}$ in length, $1 \mu \mathrm{m}$ in width and has a height of approximately $60 \mathrm{~nm}$. This specific type of electrode is commonly referred to as an ultramicroelectrode since it has at least one critical dimension of less than $25 \mu \mathrm{m}$ (Danis et al., 2015). Ultramicroelectrodes also known as UME's have been developed for a wide range of applications including heavy metal detection (Orozco et al., 2010), single cell electrochemical measurements (Ciobanu et al., 2008) in addition to glucose (Hrapovic and Luong, 2003), DNA (Authier et al., 2001), bacteria (Lee et al., 2016) and virus detection (Dick et al., 2016).

Previous work carried out in our group has demonstrated mediated glucose detection on-chip at single gold nanowires fabricated in a similar manner as those described within this article (Dawson et al., 2012). However, in that work, external reagents ferrocene monocarboxylic acid and glucose oxidase were employed for glucose detection. Whilst studies have explored both mediator-free glucose detection and the use of UME's towards glucose sensing, here, we present for the first time the use of B-cyclodextrin and o-phenylenediamine (o-PD) for the 
electrochemical deposition of glucose oxidase on to a single microfabricated band electrode (See Scheme 1.) for on-chip mediator-free glucose detection. Removal of redox mediators can simplify device fabrication, reduce costs as well as eliminate potential toxicity problems associated with next-generation electrochemical bio-sensors (Zhao et al., 2015). A key advantage of using ultra-microelectrodes is that they benefit from radial mass transport and the sensors developed herein are not limited by local oxygen diffusion to the electrode surface unlike their larger macro-electrode analogues (Clark Jr and Lyons, 1962). Pt-Black (Pt-B) was electrodeposited on to the band electrode as Pt-B nanostructured layers can provide a high catalytic surface for $\mathrm{H}_{2} \mathrm{O}_{2}$ oxidation (Tsopela et al., 2014) as well as increasing the active surface area for the electro-polymerized mixture containing GOx. o-PD has been used to immobilize a number of oxidase based enzymes onto electrodes towards diagnostic (Mousa et al., 2019), wearable (Barrett et al., 2019) and in-vivo based biosensors (Ganesana et al., 2019). o-PD is known for its ability to eliminate interferences from the electroactive species ascorbic acid (Garjonyte and Malinauskas, 1999) and uric acid (Li et al., 2016) at the electrode surface. $\beta$-cyclodextrin was incorporated in to the mixture as it has been shown to further mitigate against interference effects in the presence of o-PD (Monti et al., 2018). The device demonstrated analysis in sample volumes of $50 \mu$ utilizing an on-device reference and counter electrode. The sensor developed demonstrated excellent performance in phosphate based buffer solutions in the presence of interfering species as well as measuring glucose levels within a linear range appropriate to physiological glucose concentrations ( 4-7 mM) (Bruen et al., 2017).

\section{Materials and Methods}

\subsection{Materials}

Ferrocenemonocarboxylic acid (FcCOOH), phosphate buffered saline (PBS), ophenylenediamine (o-PD), $\beta$-cyclodextrin, sodium sulphate, sodium phosphate monobasic, sodium phosphate dibasic, chloroplatanic acid hexahydrate, lead acetate trihydrate, hydrogen peroxide $\left(\mathrm{H}_{2} \mathrm{O}_{2}\right) 30$ wt. \%, D-(+)-glucose, D-(-)-fructose, D-(+)-mannose, L-ascorbic acid, salicylic acid, uric acid and sulfuric acid were sourced from Sigma Aldrich Ltd. Glucose oxidase (GOx, E.C. 1.1.3.4) from Aspergillus niger was purchased from Sekisui Diagnostics Ltd (UK) ( $\leq 42.7 \mathrm{U} / \mathrm{mg})$. Fetal Bovine Serum was purchased from Thermofisher. All solutions were prepared with double distilled 18.3 $\mathrm{M} \Omega$ deionized water which was obtained by ELGAPurelab. 


\subsection{Apparatus and instrumentation}

Electrochemical measurements were performed using an Autolab potentiostat PGSTAT302N electrochemical workstation (Metrohm). A custom-made chip holder was used to connect the chip to the potentiostat (See supplementary material S1 A). The silicon chip was fabricated to contain six individually addressable single microband working electrodes (WE's), a gold planar band electrode which was used as a CE and a platinum planar band electrode was employed as a pseudo RE (see supplementary material S1 B and C). Microscopy images were acquired using an olympus camera and epifluorescence microscope Model BX51 TRF SN 5M18343. Scanning electron microscopy (SEM) and atomic force microscopy (AFM) images were obtained with a Zeiss Supra 40 SEM and a VEECO Dimension 3100 Atomic Force Microscope. X-Ray Photoelectron Spectroscopy (XPS) measurements were performed at the University of Limerick using a Kratos AXIS ultra spectrometer equipped with a mono Al Ka $\mathrm{X}$-ray gun. Survey and high-resolution scans were recorded with a $1 \mathrm{eV}$ and $0.05 \mathrm{eV}$ resolution, respectively. Recorded measurements were imported into OriginPro 2016 for data curation.

\subsection{Sensor preparation}

Single microband electrodes were fabricated using a standard silicon microfabrication approach including lithography, deposition and etching on silicon wafers as described previously (Dawson et al., 2013, Wahl et al., 2014, Robinson et al., 2020). Prior to use, chips (see Scheme $1 \mathrm{~A}$ ) were cleaned by ultrasonication in isopropanol, acetone and deionized water for 5 minutes each. The modification process (see Scheme $1 \mathrm{~B}$ ), firstly involved a deposition of a platinum-black layer via amperometric electrodeposition from a solution containing 15 $\mathrm{mM}$ hexachloroplatanic acid and $2.1 \mathrm{mM}$ lead acetate at $-0.75 \mathrm{~V}$ against the on-chip platinum $\mathrm{RE}$ for 10 seconds. The o-PD/ $\beta$-cyclodextrin/GOx mixture was then electrodeposited at a constant potential of $0.35 \mathrm{~V}$ versus the on chip Pt RE for 1200 seconds. Both electrochemical chronoamperograms can be viewed in the supplementary material (S2 A and B). Electropolymerization was carried out from a solution consisting of a mixture of $5 \mathrm{mM}$ o-PD, $2.5 \mathrm{mM}$ sulphonated- $\beta$-cyclodextrin, $5 \mathrm{mM}$ sodium sulphate and $10 \mathrm{mg} / \mathrm{ml}$ of $\mathrm{GOx}$ in a $50 \mathrm{mM}$ phosphate buffer (PB) (sodium phosphate monobasic and sodium phosphate dibasic) solution at $\mathrm{pH}$ 7.4. Following electrode modification, WE's were rinsed with $50 \mathrm{mM}$ PB to remove any unbound enzyme from the electrode surface. The chips were then stored in $50 \mathrm{mM} \mathrm{PB}(\mathrm{pH} 7.4)$ overnight at $4{ }^{\circ} \mathrm{C}$ prior to measurements to allow the biosensor to stabilize. 
A
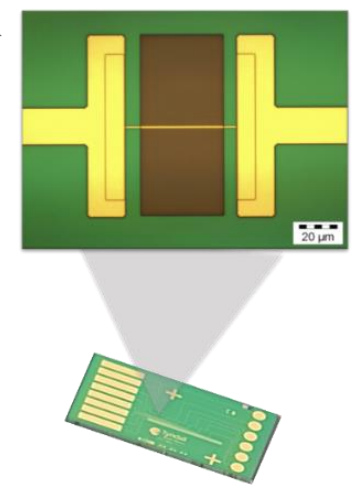

B

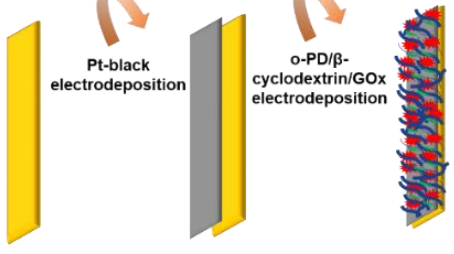

C

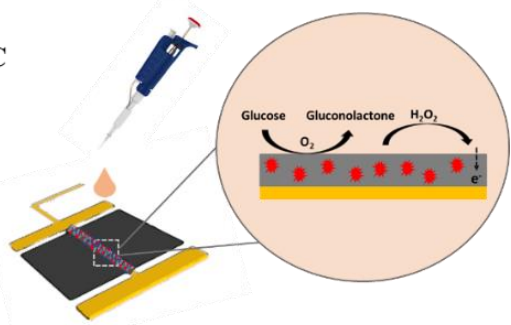

Scheme 1. A) The chip platform with a magnified image of the single microband electrode (50x microscopy image) B) The modification process for enzyme immobilization on to the single microband electrode and C) Schematic representation of the glucose detection mechanism at the electrode solution interface.

\subsection{Sensor Characterisation}

$\mathrm{CV}$ in $0.5 \mathrm{M} \mathrm{H}_{2} \mathrm{SO}_{4}$ was carried out on the bare gold electrode to assess for gold oxide formation and removal. Cyclic Voltammetry (CV) and electrochemical impedance spectroscopy (EIS) were carried out following each surface modification step in a $1 \mathrm{mM}$ $\mathrm{FcCOOH}$ redox probe. The charge transfer process occurring at the electrode-solution interface was measured using EIS following each electrodeposition. The impedance measurements were carried out over the frequency range from $100 \mathrm{mHz}$ to $100 \mathrm{kHz}$ at a potential of $200 \mathrm{mV}$. The amplitude of the alternating voltage was $5 \mathrm{mV}$. o-PD concentration (mM) was examined against a $0.5 \mathrm{mM}$ glucose addition at the electrode surface (See supplementary material S3). SEM images were obtained to visualize changes in the surface morphology between the bare $\mathrm{Au}, \quad \mathrm{Pt}$ modified and o-PD/ $\beta$-cyclodextrin/GOx microband surfaces. Finally, XPS measurements were conducted on electrode modifications at a macro Au band electrode (90 $\mu \mathrm{m} \times 7 \mathrm{~mm}$ ) as the dimensions of the microband electrodes were unsuitable to the resolution needed for XPS analysis (see supplementary material S4). These modifications could not be conducted with the on-chip RE and $\mathrm{CE}$ and thus were conducted with an external $\mathrm{Ag} / \mathrm{AgCl} \mathrm{RE}$ and Pt wire. The o-PD deposition was conducted at $0.45 \mathrm{~V}$ and the Pt deposition at $-0.5 \mathrm{~V}$, the deposition time remained the same as those described in section 2.3. 


\subsection{Electrochemical measurements}

In this study, glucose detection is quantified from enzymatically produced hydrogen peroxide; for this reason the $\mathrm{o}-\mathrm{PD} / \beta$-cyclodextrin surface modification was tested in various concentrations of hydrogen peroxide to ensure that $\mathrm{H}_{2} \mathrm{O}_{2}$ detection was possible at the modified UME in the absence of the GOx enzyme. Both linear sweep voltammetry (LSV) and chronoamperometric techniques were utilized to measure the response of glucose additions at the o-PD/ $\beta$-cyclodextrin/GOx electrode surface in $50 \mathrm{mM} \mathrm{PB}(\mathrm{pH} 7.4)$ against the on chip RE and CE. Chronoamperometric techniques were then used to evaluate the selectivity of the sensor in the presence of common interfering species. Lastly, measurements were conducted with $100 \%$ fetal bovine serum spiked with known glucose concentrations to assess sensor performance in a bio-fluid based environment.

\section{Results and Discussion}

\subsection{Characterisation}

$\mathrm{CV}$ was used to examine microelectrode behaviour in the presence of the electroactive probe $1 \mathrm{mM}$ FcCOOH. The resultant CVs exhibit quasi steady-state behaviour (Figure $1 \mathrm{~A}$ ), arising from radial diffusion mass transport to the electrode, indicative of ultramicroband electrodes. The single band sensors demonstrated excellent intra-chip reproducibility as an RSD of less than $0.1 \%$ was determined between five WE's measured in $1 \mathrm{mM} \mathrm{FcCOOH}$ at a scan rate of $50 \mathrm{mVs}^{-1}$. This also indicated that the on-chip RE and CE were effective for electrochemical measurements. The current generated $(2 \mathrm{nA})$ confirms that electron transfer is taking place at the ultra-microband electrode. Furthermore, it confirms that the passivation layer inhibits any unwanted electrochemical responses from occurring at other metallised regions on the chip. For comparison purposes, a CV was carried out on a macro Au band electrode (dimensions 90 $\mu \mathrm{m} \times 7 \mathrm{~mm})$ under the same conditions $\left(50 \mathrm{mVs}^{-1}\right.$ scan rate) versus an $\mathrm{Ag} / \mathrm{AgCl} \mathrm{RE}$ and using a $\mathrm{Pt}$ wire as the $\mathrm{CE}$, a peak shaped $\mathrm{CV}$ was produced depicting planar diffusion to the larger band electrode (see inset Figure 1 A). As expected, higher current densities exist at the microband electrode owing to the radial diffusion regime in comparison to the macroelectrode, demonstrating the higher sensitivity associated with microelectrodes. An AFM characterization was undertaken and a typical micrograph (5-micron size) obtained at the clean bare gold band electrode is presented in Figure $1 \mathrm{~B}$. This data confirmed the electrode width to be 1 micron. An RMS value of less than $1 \mathrm{~nm}$ was measured which was expected for e-beam evaporated gold electrodes. Cyclic voltammetry in sulfuric acid can be used to characterize gold electrodes, 
to show the formation of surface oxides during oxidation and their removal during the preceding negative sweep (Buk and Pemble, 2019). A typical voltammogram of the Au microband electrode is shown in Figure $1 \mathrm{C}$. An oxidation peak can be seen at $0.9 \mathrm{~V}$ versus the on-chip platinum RE electrode. This peak represents the formation of the gold oxide $\left(\mathrm{Au}_{2} \mathrm{O}_{3}\right)$. During the reverse sweep, a peak can be seen at $0.29 \mathrm{~V}$ resulting from the removal of the gold oxide layer.
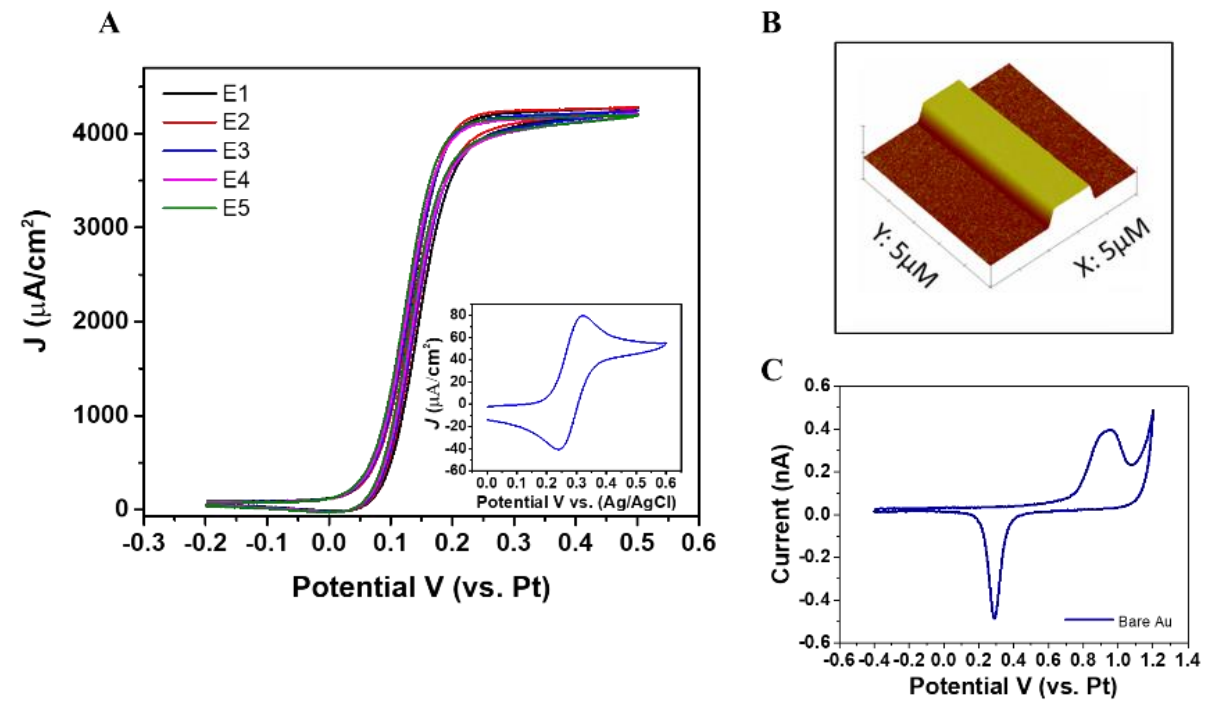

Figure 1. A) Cyclic voltammogram obtained in $1 \mathrm{mM} \mathrm{FcCOOH}$ in $50 \mathrm{mM}$ PBS (pH 7.4) for $\mathrm{n}=5$ electrodes on one chip ( $\mathrm{RSD}<0.1 \%$ ), (inset graph shows a cyclic voltammogram obtained at a macro Au band electrode under the same conditions with an external $\mathrm{Ag} / \mathrm{AgCl}$ reference electrode) B) Atomic force microscopy image of a 5 $\mu \mathrm{m} \times 5 \mu \mathrm{m}$ area at a scan rate of $0.7 \mathrm{~Hz}$, (Background plane subtraction was applied to the image) and C) Cyclic voltammogram obtained in $0.5 \mathrm{M} \mathrm{H}_{2} \mathrm{SO}_{4}$ at a scan rate of $50 \mathrm{mVs}^{-1}$.

Following each step of the fabrication process, a number of techniques were employed to understand the changes to the surface properties. CV was used to obtain voltammograms in the $1 \mathrm{mM} \mathrm{FcCOOH}$ redox reagent after each modification (Figure $2 \mathrm{~A}$ ). An increase in oxidation current of around $4 \mathrm{nA}$ was evident between the $\mathrm{Au}$ (Blue) and $\mathrm{Pt}$-modified (green) surface (at $0.2 \mathrm{~V}$ ) resulting from the enhanced electroactive area of the Pt-B modification. A clear decrease in both oxidation and reduction currents is visible after the o-PD/ $\beta$-cyclodextrin/GOx deposition which can be attributed to the formation of the o-PD layer (Liu et al., 2015). EIS was then employed to assess the change in charge transfer following each electrodeposition (Figure 2 B). Nyquist plots can include a semi-circular region and a linear part. At higher 
frequencies, the semicircular region corresponds to the electron transfer limited process, and the diameter is equivalent to the electron transfer resistance $\left(R_{c t}\right)$. The linear part at lower frequencies corresponds to the diffusion process (Rezaei et al., 2015). The $\mathrm{R}_{\mathrm{ct}}$ decreased from $217 \mathrm{M} \Omega$ at the bare $\mathrm{Au}$ surface to $151 \mathrm{M} \Omega$ following the introduction of an enhanced surface area $\mathrm{Pt}$ electrodeposition. Following o-PD/ $\beta$-cyclodextrin/GOx deposition, under the same parameters a full semi-circle was not obtained for an electrochemical circle fit, however, there is a clear change in impendence behaviour, this final layer is acting as a barrier to electron transfer of the redox probe. No diffusion-controlled effect was observed, as the electrodes were diffusionally independent. All CV data supported the results of the EIS.
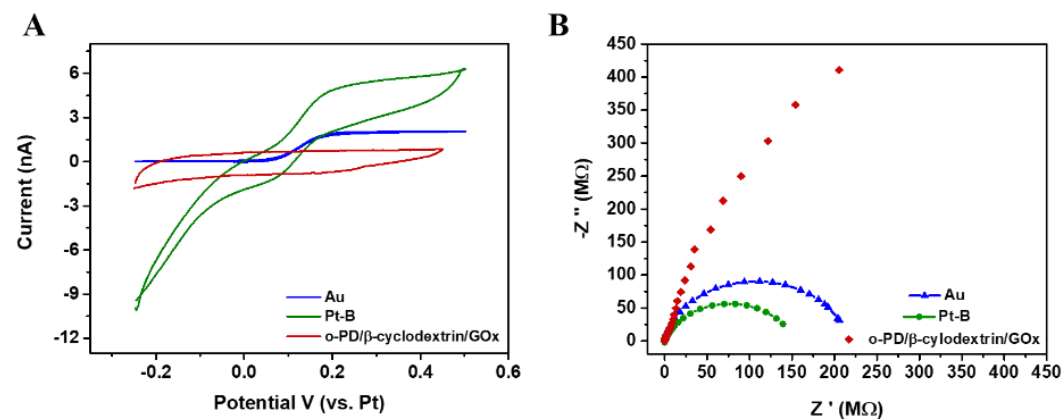

Figure 2. A) $\mathrm{CV}$ in $1 \mathrm{mM} \mathrm{FcCOOH}$ in $10 \mathrm{mM} \mathrm{PBS}\left(\mathrm{pH} \mathrm{7.4)}\right.$ at $50 \mathrm{mVs}^{-1}$, at the bare gold (blue), platinum-black modified (green) and o-PD/ $\beta$-cyclodextrin/GOx modified (red) microband electrode, B) Nyquist plots obtained in $1 \mathrm{mM} \mathrm{FcCOOH}$ in $10 \mathrm{mM}$ PBS, on a bare gold (blue) [Rct $217 \mathrm{M} \Omega$ ], platinum black modified (green) [Ret $151 \mathrm{M} \Omega$ ] and o-PD/ $\beta$ cyclodextrin/GOx modified [unfitted data] (red).

Scanning electron microscopy images confirmed the presence of a nanodentritic Pt coating on to the $1 \mu \mathrm{m}$ band electrode with a clear change in surface morphology (see Figure 3 A 1-2). Following the o-PD/ $\beta$-cyclodextrin/GOx deposition subtle changes to dendrite thickness were observed however this was not quantifiable (see Figure 3 A-3). In order to quantify the effectiveness of electrodepositions as a modification method a larger macroband electrode was modified amperometrically with both Pt-B and o-PD/ $\beta$-cyclodextrin. XPS surveys obtained at each electrode modification demonstrate a change in the surface composition. Firstly, Figure 3 $\mathrm{B}$ depicts the introduction of a platinum peak $\mathrm{Pt} 4 \mathrm{f}$ post $\mathrm{Pt}-\mathrm{B}$ deposition. The atomic percentage of $\mathrm{Pt}$ decreased to $0.2 \%$ following the electrodeposition of the $\mathrm{o}-\mathrm{PD} / \beta$-cyclodextrin layer. Quantification of each electrode modification can be found in table 1 of the supporting information. The presence of the Pt $4 \mathrm{f}$ peak following o-PD/ $\beta$-cyclodextrin deposition may be attributed to an ultra-thin electro-polymerization layer, this may also be the result of a non- 
uniform electrodeposition on the Pt modified electrode. Following the o-PD/ $\beta$-cyclodextrin deposition, the introduction of an amine group $(\mathrm{C}-\mathrm{N})$ can be seen within the high-resolution XPS survey of the N1s peak layer 3 (Figure 3 C). Similarly, the high-resolution scan of the C1s peak shows the introduction of an amine group (Figure $3 \mathrm{D}$ ) indicating that the o-PD layer has successfully electrodeposited. XPS measurements confirmed the presence of both Pt-B and oPD on a larger gold band electrode fabricated on the silicon substrate.

$\mathbf{A}$
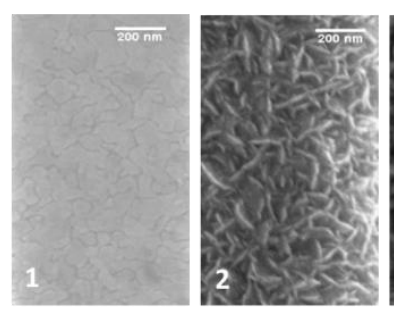

C

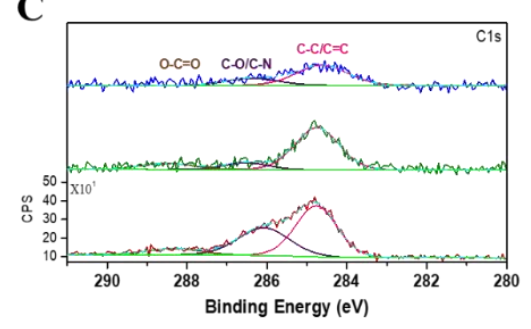

B
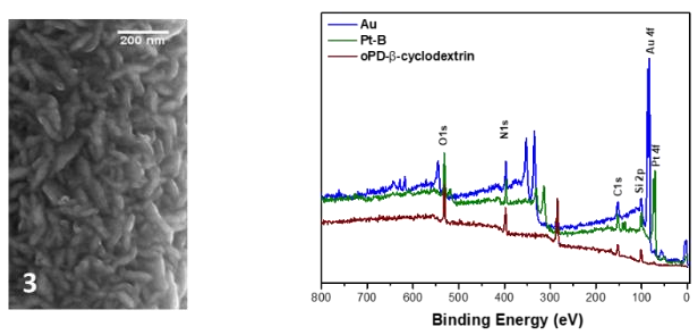

D

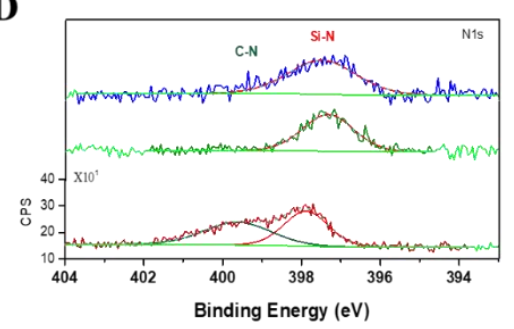

Figure 3. A) Scanning electron microscopy images taken at (1) Bare gold electrode surface (2) Pt-B modified electrode surface and (3) Pt-B/o-PD/ $\beta$-cyclodextrin/GOx modified electrode surface B) XPS survey scan of clean bare gold (blue), as modified Pt-B (green), and as modified $\mathrm{Pt}-\mathrm{B} / \mathrm{o}-\mathrm{PD} / \beta$-cyclodextrin (red), C) High resolution scans of the $\mathrm{C} 1 \mathrm{~s}$ peaks D) High resolution scans of the N1s peaks.

\subsection{Electrochemical measurements}

$\mathrm{H}_{2} \mathrm{O}_{2}$ has been commonly explored in electrochemical bioanalysis as it forms part of the reactive oxygen species which play a crucial role in intracellular signalling (Prasad et al., 2016). In addition to this, $\mathrm{H}_{2} \mathrm{O}_{2}$ is widely used for the indirect detection of biomolecules such as glutamate, acetlylcholine as well as glucose (Sanford et al., 2010). As previously mentioned, in this work glucose is measured from enzymatically produced hydrogen peroxide, whilst it was expected that $\mathrm{H}_{2} \mathrm{O}_{2}$ can permeate o-PD modification layers (Rothwell et al., 2008) we 
confirmed this utilizing $\mathrm{CV}$ in various concentrations of $\mathrm{H}_{2} \mathrm{O}_{2}$. Figure 4 A displays LSV measurements obtained in increasing concentrations of $\mathrm{H}_{2} \mathrm{O}_{2}$ at the $\mathrm{o}-\mathrm{PD} / \beta$-cyclodextrin surface. An increasing faradaic current was observed with increasing concentrations, ranging from $0.5 \mathrm{mM}$ to $2.5 \mathrm{mM}$ of $\mathrm{H}_{2} \mathrm{O}_{2}$. These results show that $\mathrm{H}_{2} \mathrm{O}_{2}$ can penetrate through the modification layer to reach the underlying platinum-modified surface and undergo electrochemical oxidation. A plot of peak current versus $\mathrm{H}_{2} \mathrm{O}_{2}$ concentration is presented in Figure $4 \mathrm{~B}$. The plot exhibits good linearity $\left(\mathrm{COD} \mathrm{R}^{2}=0.993\right)$ indicating that the sensor response to hydrogen peroxide is linear within this concentration range. The sensitivity of the sensor was determined from the slope of the line to be $3.89 \mathrm{nA} \mathrm{mM}^{-1}$. The theoretical LOD was determined to be $17 \mu \mathrm{M}$ using the blank method: $3 S_{b} / m$, where $S_{b}$ is the standard deviation of the blank and $\mathrm{m}$ is slope of the line (Švorc and Kalcher, 2014). Both linear sweep voltammetry and chronoamperometry techniques were employed for on-chip glucose measurements in six pre-determined aliquots of glucose (2.5 mM to $15 \mathrm{mM})$ made up in $50 \mathrm{mM}$ $\mathrm{PB}$ ( $\mathrm{pH}$ 7.4). Figure $4 \mathrm{C}$ displays the linear sweep voltammograms from 0 to $0.4 \mathrm{~V}$, an increase in current is seen with increasing glucose concentrations in the range of $2.5 \mathrm{mM}$ to $15 \mathrm{mM}$ $\left(C O D R^{2}=0.998\right)$ (Figure $\left.4 \mathrm{D}\right)$. Sensitivity was obtained from the slope of the calibration plot and was determined to be $0.13 \mathrm{nA} \mathrm{mM}^{-1}$. The theoretical LOD was determined to be $1.42 \mathrm{mM}$ for the LSV technique. Figure $5 \mathrm{E}$ displays the chronoamperometric response of the microband at $0.25 \mathrm{~V}$ for 45 second measurements in the same aliquots of glucose. The biosensor reached a steady-state response within 20 seconds of applying a potential. A plot of current versus glucose concentration is presented in Figure $4 \mathrm{~F}$ where a linear increase in current is seen with increasing glucose concentrations $\left(\mathrm{COD} \mathrm{R}^{2}=0.997\right)$. The sensitivity here was found to be 0.15 $\mathrm{nA} \mathrm{mM}{ }^{-1}$ for the chronoamperometric method with a theoretical LOD of $0.79 \mathrm{mM}$. For a $5 \mathrm{mM}$ glucose concentration the RSD between chronoamperometric measurements at 3 separate chips was determined to be $10.3 \%$. For the LSV technique at the same concentration, the RSD was determined to be $11.6 \%$. For a $12.5 \mathrm{mM}$ glucose concentration, the RSD was found to increase to $18 \%$ for the chronoamperometric method and was determined to be $13.9 \%$ for the LSV technique. 

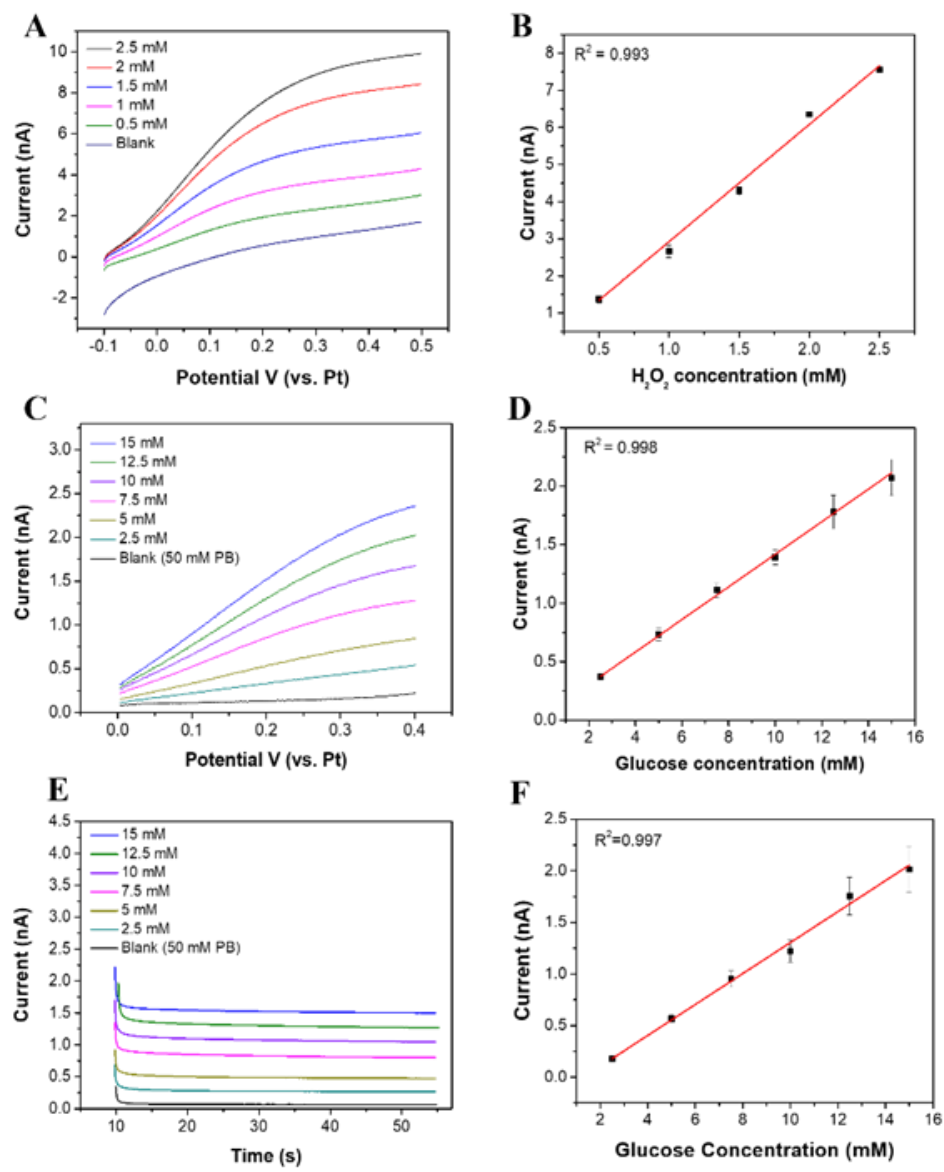

Figure $4 \mathrm{~A}$ ) LSV in $1 \mathrm{mM} \mathrm{H} \mathrm{O}_{2}$ at the Pt modified band (green) and at the $\mathrm{Pt} / \mathrm{o}-\mathrm{PD} / \beta$ cyclodextrin/GOx modified band (red) B) LSV obtained in increasing concentrations of $\mathrm{H}_{2} \mathrm{O}_{2}$ at $\mathrm{o}-\mathrm{PD} / \beta$-cyclodextrin surface $\mathrm{C}$ ) Corresponding calibration obtained from background subtracted data at $0.25 \mathrm{~V}$, (The error bars represent the standard error between the mean current of $n=3$ chips) D) Linear sweep voltammograms at a scan rate of $50 \mathrm{mVs}^{-1}$ from 0 to $0.4 \mathrm{~V}$ in increasing glucose concentrations in $50 \mathrm{mM} \mathrm{PB}$ solution ( $\mathrm{pH} 7.4)$, E) The resulting calibration obtained at $0.25 \mathrm{~V}, \mathrm{E}$ ) i-t curves for the chronoamperometric response of the biosensor to increasing glucose concentrations from $2.5 \mathrm{mM}$ up to $15 \mathrm{mM}$ in $50 \mathrm{mM}$ PB (pH 7.4), F) The resulting calibration curve, (The error bars represent the standard error between the mean current of $n=3$ chips, the mean current of each sensor was determined from 30 data points after $30 \mathrm{~s})$.

\subsubsection{Interference and foetal bovine serum measurements}

Chronoamperometry was applied for both interference and real sample analysis owing to some of the advantages associated with amperometric measurements, as an example, amperometry can be beneficial towards reducing power consumption. Figure 5 A displays the responses of 
the biosensor towards a $2.5 \mathrm{mM}$ glucose concentration and that of a $2.5 \mathrm{mM}$ glucose solution containing either $0.5 \mathrm{mM}$ L-ascorbic acid, $1 \mathrm{mM}$ fructose, $1 \mathrm{mM}$ maltose, $1 \mathrm{mM}$ uric acid and $0.5 \mathrm{mM}$ salicylic acid. The interference effect was calculated using the following equation; $\left[\frac{I_{\text {glucose }}}{I_{\text {interference }}}\right] * 100$. Response changes are tabulated in the supplementary information (see Table 3.). No noticeable change in current was observed in the presence of interfering species indicating that the biosensor is selective to glucose measurements. A number of investigations examining glucose levels in spiked serum samples have been undertaken in serum solutions diluted in PBS (Mehmeti et al., 2017) (Vijayaraj et al., 2016), in this study the electrode response was measured in $100 \%$ fetal bovine serum to evaluate the sensor performance in an un-diluted biological serum. The fetal bovine serum was spiked with known concentrations of glucose and a chronoamperometric response was measured for 70 seconds at $0.25 \mathrm{~V}$. A linear response was observed in the range of $2-12 \mathrm{mM}$ (Figure $5 \mathrm{C}$ ). Measurements conducted in fetal bovine serum showed a clear decrease in measured current (see Figure $5 \mathrm{C}$ and D) in comparison to the calibration obtained in buffer based solution (see Figure $4 \mathrm{C}$ and $\mathrm{D}$ ). This reduction in signal may be a result of non-specific adsorption or precipitation of agents present within fetal bovine serum to the ultramicroelectrode and/or the on-chip RE and CE electrodes. Despite the decrease in current, a linear response was observed for increasing glucose concentrations in the range of $2-12 \mathrm{mM}$ (see Figure $5 \mathrm{C}$ ) indicating the potential for glucose detection in serum based environments. 

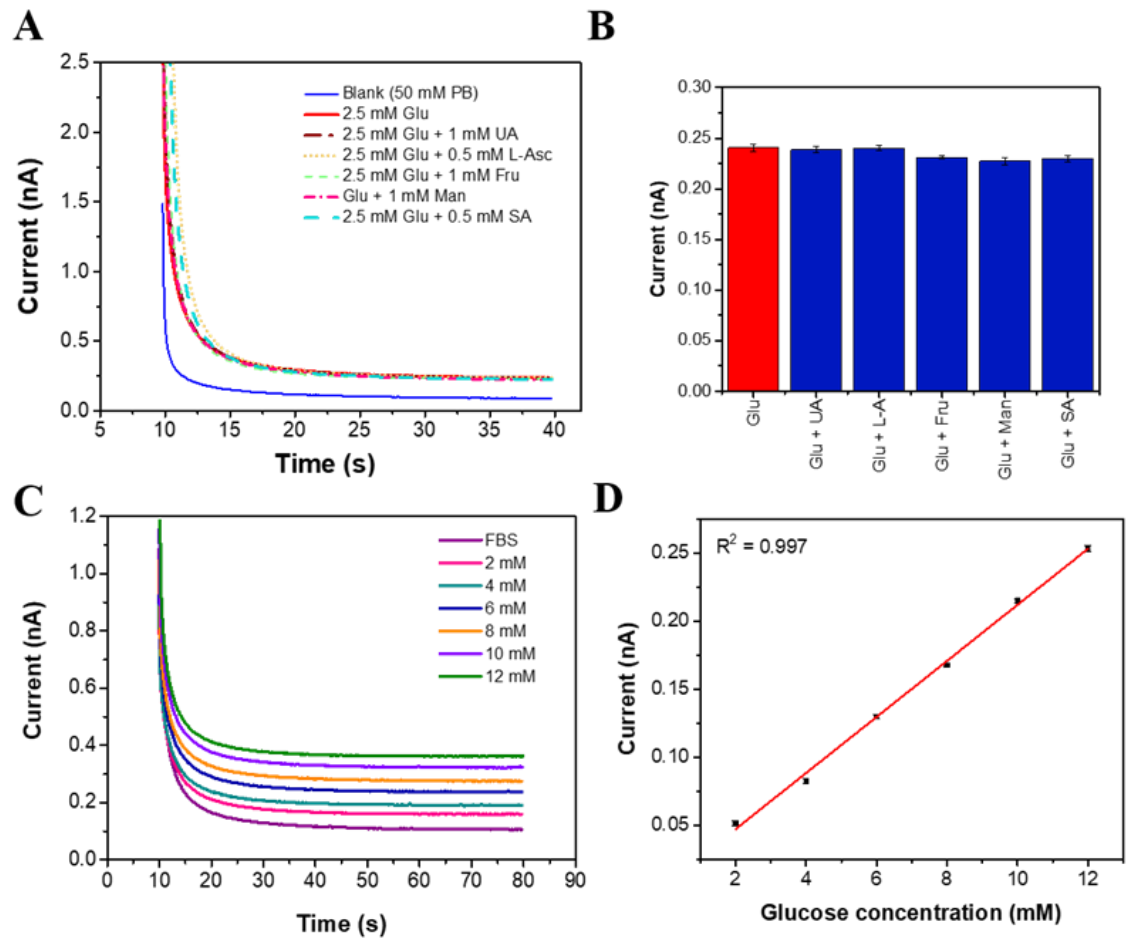

Figure 5. A) Chronoamperometric response of the on-chip biosensor to a blank solution (50mM PB, pH 7.4), to $2.5 \mathrm{mM}$ Glucose and to a further separate 5 aliquots of $2.5 \mathrm{mM}$ glucose + other potential interfering species (uric acid (UA), L-ascorbic acid (L-A) Fructose (Fru), Mannose (Man) and Salicylic acid (SA). B) Bar chart depicting the background subtracted currents of a $2.5 \mathrm{mM}$ Glucose solution and that of a $2.5 \mathrm{mM}$ Glucose solution containing the interfering species as listed in A, (Error bars represent std. dev between 50 data points obtained from 20-40 s current sampling time of measurement) C) i-t curves for the chronoamperometric response of the sensor in $100 \%$ fetal bovine serum spiked with known concentrations of glucose D) corresponding calibration graph for figure C, (Error bars represent std. dev between 50 data points obtained from the current sampling time of $40-80 \mathrm{~s}$ of the measurement)

A number of publications on enzymatic based glucose biosensors constructed on miniaturized electrodes for sensing in biological based samples have been tabulated in the supplementary material (Table 3). In comparison with these electrochemical biosensors this work offers a miniaturized electroanalytical chip capable of measuring glucose concentrations on-chip over a linear range applicable to sensing in bio-fluids such as blood and interstitial fluid (Heikenfeld et al., 2019). Sensing capabilities were demonstrated on-chip in comparison to many devices incorporating the conventional electrochemical set up with an external RE. The sensitivity values determined for both the LSV and chronoamperomeric techniques are comparable with 
other microelectrodes presented which utilize a WE area close in surface area to the microband presented here.

\section{Conclusions and future perspectives}

In summary, we have demonstrated a simple two-step electrochemical modification to a single gold microband electrode fabricated on a miniaturized electroanalytical device towards on-chip glucose detection in low sample volumes. SEM confirmed a change in surface morphology following each electrodeposition step. The electrochemical characteristics of the microbands were analyzed in $1 \mathrm{mM} \mathrm{FcCOOH}$ with EIS data demonstrating a clear change in the $\mathrm{R}_{\mathrm{ct}}$ following each electrode modification. XPS confirmed the presence of the electrodeposited Pt coating and the o-PD layer on a macro band electrode fabricated on the silicon chip indicating that electrodepositions were a suitable technique for electrode modification. Electropolymerization of the o-PD/ $\beta$-cyclodextrin/GOx layer was successful in immobilizing the enzyme on the surface of the microelectrode resulting in glucose detection over a linear range of $2.5 \mathrm{mM}$ to $15 \mathrm{mM}$ in buffer-based solutions. Both chronoamperometry and LSV methods employed for glucose detection at the UME demonstrated linear detection for six predetermined aliquots of glucose $(2.5 \mathrm{mM}$ to $15 \mathrm{mM})$. Chronoamperometric measurements carried out in $100 \%$ fetal bovine serum show a reduction in signal response in comparison to measurements carried out in phosphate-based buffers. However, the UME demonstrated a linear response to increasing glucose concentrations ( $2 \mathrm{mM}$ to $12 \mathrm{mM})$. Future work on this platform should focus on optimization and reproducibility of electrode materials within target media in addition to testing electrodes over a period to understand the monitoring capabilities of miniaturized electrodes. 
Supplementary Materials: Supplementary materials have been mentioned within the document and have been attached with the submission.

Author Contributions: J.M performed the experiments and completed the writing and data curation. F.L. conducted XPS analysis. C.B. contributed to methodologies and formal analysis. M.T, P.G and A.O.R contributed to supervision, writing, reviewing and editing the document. P.G and A.O.R contributed to funding acquisition.

Funding: This research was supported by Science Foundation Ireland (SFI) through the Insight Centre for Data Analytics Initiative, grant number SFI/12/RC/2289 and X

Acknowledgments: We are grateful to Dr. Caoimhe Robinson for help with AFM analysis and Dr. Sofia Teixeira for helpful discussions on impedance data.

Conflicts of Interest: The authors declare no conflicts of interest.

\section{References}

Amines, Aromatic, Phenylenediamines. Kirk-Othmer Encyclopedia of Chemical Technology.

AUTHIER, L., GROSSIORD, C., BROSSIER, P. \& LIMOGES, B. 2001. Gold Nanoparticle-Based Quantitative Electrochemical Detection of Amplified Human Cytomegalovirus DNA Using Disposable Microband Electrodes. Analytical Chemistry, 73, 4450-4456.

BARRETT, C., O'SULLIVAN, F., BARRY, S., GRYGORYEV, K., O'GORMAN, D., O'MAHONY, C. \& O'RIORDAN, A. Novel Surface Modified Polymer Microneedle based Biosensors for Interstitial Fluid Glucose Detection. 2019 IEEE SENSORS, 27-30 Oct. 2019 2019. 1-4.

BRUEN, D., DELANEY, C., FLOREA, L. \& DIAMOND, D. 2017. Glucose Sensing for Diabetes Monitoring: Recent Developments. Sensors, 17, 1866.

BUK, V. \& PEMBLE, M. E. 2019. A highly sensitive glucose biosensor based on a micro disk array electrode design modified with carbon quantum dots and gold nanoparticles. Electrochimica Acta, 298, 97-105.

CINTI, S., MARRONE, R., MAZZARACCHIO, V., MOSCONE, D. \& ARDUINI, F. 2020. Novel bio-lab-on-a-tip for electrochemical glucose sensing in commercial beverages. Biosensors and Bioelectronics, 165, 112334.

CIOBANU, M., TAYLOR, D. E., WILBURN, J. P. \& CLIFFEL, D. E. 2008. Glucose and Lactate Biosensors for Scanning Electrochemical Microscopy Imaging of Single Live Cells. Analytical Chemistry, 80, 2717-2727.

CLARK JR, L. C. \& LYONS, C. 1962. ELECTRODE SYSTEMS FOR CONTINUOUS MONITORING IN CARDIOVASCULAR SURGERY. Annals of the New York Academy of Sciences, 102, 29-45.

CORRADINI, S., PILOSIO, B., DONDI, F., LINARI, G., TESTA, S., BRUGNOLI, F., GIANELLA, P., PIETRA, M. \& FRACASSI, F. 2016. Accuracy of a Flash Glucose Monitoring System in Diabetic Dogs. Journal of Veterinary Internal Medicine, 30, 983-988.

DANIS, L., POLCARI, D., KWAN, A., GATEMAN, S. M. \& MAUZEROLL, J. 2015. Fabrication of Carbon, Gold, Platinum, Silver, and Mercury Ultramicroelectrodes with Controlled Geometry. Analytical Chemistry, 87, 2565-2569.

DAWSON, K., BAUDEQUIN, M., SASSIAT, N., QUINN, A. J. \& O’RIORDAN, A. 2013. Electroanalysis at discrete arrays of gold nanowire electrodes. Electrochimica Acta, 101, 169-176.

DAWSON, K., WAHL, A., MURPHY, R. \& O'RIORDAN, A. 2012. Electroanalysis at Single Gold Nanowire Electrodes. The Journal of Physical Chemistry C, 116, 14665-14673.

DICK, J. E., HILTERBRAND, A. T., STRAWSINE, L. M., UPTON, J. W. \& BARD, A. J. 2016. Enzymatically enhanced collisions on ultramicroelectrodes for specific and rapid detection of individual viruses. Proceedings of the National Academy of Sciences, 113, 6403-6408.

FEKETE, Z. 2015. Recent advances in silicon-based neural microelectrodes and microsystems: a review. Sensors and Actuators B: Chemical, 215, 300-315. 
GANESANA, M., TRIKANTZOPOULOS, E., MANIAR, Y., LEE, S. T. \& VENTON, B. J. 2019. Development of a novel micro biosensor for in vivo monitoring of glutamate release in the brain. Biosensors and Bioelectronics, 130, 103-109.

GARJONYTE, R. \& MALINAUSKAS, A. 1999. Amperometric glucose biosensor based on glucose oxidase immobilized in poly(o-phenylenediamine) layer. Sensors and Actuators B: Chemical, 56, 85-92.

HEIKENFELD, J., JAJACK, A., FELDMAN, B., GRANGER, S. W., GAITONDE, S., BEGTRUP, G. \& KATCHMAN, B. A. 2019. Accessing analytes in biofluids for peripheral biochemical monitoring. Nature Biotechnology, 37, 407-419.

HRAPOVIC, S. \& LUONG, J. H. T. 2003. Picoamperometric Detection of Glucose at Ultrasmall Platinum-Based Biosensors: Preparation and Characterization. Analytical Chemistry, 75, 3308-3315.

JIN, D. S., ZHU, X., BRIGHTBILL, E. L., BROWN, B. \& VOGEL, E. M. 2020. Chemical and Biological Sensor Capsules for Real-Time Measurement of Cell Properties in Bioreactors. ECS Meeting Abstracts, MA202001, 1904-1904.

LEE, J. Y., KIM, B.-K., KANG, M. \& PARK, J. H. 2016. Label-Free Detection of Single Living Bacteria via Electrochemical Collision Event. Scientific Reports, 6, 30022.

LI, D., LIN, C., BATCHELOR-MCAULEY, C., CHEN, L. \& COMPTON, R. G. 2019. Electrochemical measurement of the size of microband electrodes: A theoretical study. Journal of Electroanalytical Chemistry, 840, 279-284.

LI, J., KOINKAR, P., FUCHIWAKI, Y. \& YASUZAWA, M. 2016. A fine pointed glucose oxidase immobilized electrode for low-invasive amperometric glucose monitoring. Biosensors and Bioelectronics, 86, 90-94.

LI, Z., SONG, Y., XIAO, G., GAO, F., XU, S., WANG, M., ZHANG, Y., GUO, F., LIU, J., XIA, Y. \& CAI, X. 2018. Bioelectrochemical microelectrode arrays for glutamate and electrophysiology detection in hippocampus of temporal lobe epileptic rats. Analytical Biochemistry, 550, 123-131.

LISI, F., PETERSON, J. R. \& GOODING, J. J. 2020. The application of personal glucose meters as universal pointof-care diagnostic tools. Biosensors and Bioelectronics, 148, 111835.

LIU, L., CHEN, Y., LV, H., WANG, G., HU, X. \& WANG, C. 2015. Construction of a non-enzymatic glucose sensor based on copper nanoparticles/poly(o-phenylenediamine) nanocomposites. Journal of Solid State Electrochemistry, 19, 731-738.

MEHMETI, E., STANKOVIĆ, D. M., CHAIYO, S., ZAVASNIK, J., ŽAGAR, K. \& KALCHER, K. 2017. Wiring of glucose oxidase with graphene nanoribbons: an electrochemical third generation glucose biosensor. Microchimica Acta, 184, 1127-1134.

MONTI, P., ROCCHITTA, G., MARCEDDU, S., DETTORI, M. A., FABBRI, D., JAOUA, S., MIGHELI, Q., DELOGU, G. \& SERRA, P. A. 2018. Use of $\beta$-cyclodextrin as enhancer of ascorbic acid rejection in permselective films for amperometric biosensor applications. Talanta, 186, 53-59.

MOUSA, H. M., AGGAS, J. R. \& GUISEPPI-ELIE, A. 2019. Electropolymerization of aniline and (N-phenyl-ophenylenediamine) for glucose biosensor application. Materials Letters, 238, 267-270.

OROZCO, J., FERNÁNDEZ-SÁNCHEZ, C. \& JIMÉNEZ-JORQUERA, C. 2010. Ultramicroelectrode array based sensors: a promising analytical tool for environmental monitoring. Sensors (Basel), 10, 475-90.

PONTIUS, K., SEMENOVA, D., SILINA, Y. E., GERNAEY, K. V. \& JUNICKE, H. 2020. Automated Electrochemical Glucose Biosensor Platform as an Efficient Tool Toward On-Line Fermentation Monitoring: Novel Application Approaches and Insights. Frontiers in Bioengineering and Biotechnology, 8.

PRASAD, A., KIKUCHI, H., INOUE, K. Y., SUZUKI, M., SUGIURA, Y., SUGAI, T., TOMONORI, A., TADA, M., KOBAYASHI, M., MATSUE, T. \& KASAI, S. 2016. Simultaneous Real-Time Monitoring of Oxygen Consumption and Hydrogen Peroxide Production in Cells Using Our Newly Developed Chip-Type Biosensor Device. Frontiers in physiology, 7, 109-109.

REZAEI, B., BOROUJENI, M. K. \& ENSAFI, A. A. 2015. Fabrication of DNA, o-phenylenediamine, and gold nanoparticle bioimprinted polymer electrochemical sensor for the determination of dopamine. Biosensors and Bioelectronics, 66, 490-496.

ROBINSON, C., CREEDON, N., SAYERS, R., KENNEDY, E. \& O'RIORDAN, A. 2020. Electrochemical Detection of Bovine Immunoglobulins G to Determine Passive Transfer of Antibodies to Calves. Analytical Methods.

ROTHWELL, S. A., KILLORAN, S. J., NEVILlE, E. M., CROTTY, A. M. \& O’NEILL, R. D. 2008. Poly(ophenylenediamine) electrosynthesized in the absence of added background electrolyte provides a new permselectivity benchmark for biosensor applications. Electrochemistry Communications, 10, 1078-1081.

SANFORD, A. L., MORTON, S. W., WHITEHOUSE, K. L., OARA, H. M., LUGO-MORALES, L. Z., ROBERTS, J. G. \& SOMBERS, L. A. 2010. Voltammetric detection of hydrogen peroxide at carbon fiber microelectrodes. Analytical chemistry, 82, 5205-5210. 
STREETER, I., FIETKAU, N., DEL CAMPO, J., MAS, R., MŨNOZ, F. X. \& COMPTON, R. G. 2007. Voltammetry at Regular Microband Electrode Arrays: Theory and Experiment. The Journal of Physical Chemistry C, 111, 12058-12066.

ŠVORC, L'. \& KALCHER, K. 2014. Modification-free electrochemical approach for sensitive monitoring of purine DNA bases: Simultaneous determination of guanine and adenine in biological samples using borondoped diamond electrode. Sensors and Actuators B: Chemical, 194, 332-342.

TSOPELA, A., LALE, A., VANHOVE, E., REYNES, O., SÉGUY, I., TEMPLE-BOYER, P., JUNEAU, P., IZQUIERDO, R. \& LAUNAY, J. 2014. Integrated electrochemical biosensor based on algal metabolism for water toxicity analysis. Biosensors and Bioelectronics, 61, 290-297.

VIJAYARAJ, K., HONG, S. W., JIN, S.-H., CHANG, S.-C. \& PARK, D.-S. 2016. Fabrication of a novel disposable glucose biosensor using an electrochemically reduced graphene oxide-glucose oxidase biocomposite. Analytical Methods, 8, 6974-6981.

WAHL, A., BARRY, S., DAWSON, K., MACHALE, J., QUINN, A. J. \& O'RIORDAN, A. 2014. Electroanalysis at Ultramicro and Nanoscale Electrodes: A Comparative Study. Journal of The Electrochemical Society, 161, B3055-B3060.

ZHAO, M., GAO, Y., SUN, J. \& GAO, F. 2015. Mediatorless Glucose Biosensor and Direct Electron Transfer Type Glucose/Air Biofuel Cell Enabled with Carbon Nanodots. Analytical Chemistry, 87, 2615-2622. 